\title{
STUDIES AND RESEARCH ON OBTAINING MULTIFUNCTIONAL THIN FILMS BY MAGNETRON-ASSISTED PVD PROCESS
}

\author{
Simona BOICIUC \\ "Dunarea de Jos" University of Galati, Romania \\ e-mail: simonaboiciuc@yahoo.com
}

\begin{abstract}
The paper aims to obtain thin films of nickel and zinc through the magnetronassisted spraying process and their characterization from a structural point of view, of electrical, optical properties and corrosion resistance. It was found that as the intensity and discharge power increase, changes occur in the structure and properties of the deposited films.
\end{abstract}

KEYWORDS: thin films, d.c. magnetron, electrical and optical properties

\section{Introduction}

In addition to the basic function (electrical, optical, magnetic), the multifunctional coatings also have additional protection functions that ensure / increase their durability in operation.

Thin films are used for decorative - protective purposes, in electronic and optoelectronic applications, in the medical industry, as biocompatible films, in the field of mechanical parts manufacturing, to improve resistance to oxidation, corrosion, fatigue, wear, friction, to create thermal barriers and / or diffusion [1].

PVD deposition processes allow the deposition of films consisting of pure metals, oxides, nitrides, carbides whose structure can vary from porous to fibrous columnar, to compact columnar or with equiaxial grains (increasing the temperature favours recrystallization phenomena leading to polyhedral grains), depending on the submission parameters.

In the case of the magnetron-assisted PVD process, by superimposing a magnetic field parallel to the cathode surface, over the created electric field, the electrons are forced to remain for a longer time near the target, having helical trajectories. This creates a plasma with a high degree of ionization in front of the target, increases the spray rate and the deposition rate, and the pressure can be considerably reduced [1].

The deposition of pure metals by the magnetronassisted PVD process can be performed to obtain reflective surfaces, contactor contact surfaces, for the protection of plastics, metals or glass or for decorative purposes.

Nickel deposits are used in many industries due to their resistance to atmospheric corrosion, water, alkaline solutions, salt solutions, weak organic acids, dry gases containing hydrochloric acid, hydrofluoric acid up to temperatures of $500{ }^{\circ} \mathrm{C}$. In the presence of nitric acid, sulfuric acid, hydrochloric acid, sulphur compounds, condensed water vapor or moisture, halogens corrode [2, 3].

The use of nickel deposits is also due to properties such as the melting temperature of 1455 ${ }^{\circ} \mathrm{C}$, density $8.9 \mathrm{~g} / \mathrm{cm}^{3}$, specific heat of $0.105 \mathrm{cal} / \mathrm{g}{ }^{\circ} \mathrm{C}$, coefficient of linear expansion of $13.31 /{ }^{\circ} \mathrm{C}$, thermal conductivity of $0.22 \mathrm{cal} / \mathrm{cm}^{\circ} \mathrm{C}$, electrical conductivity at $20{ }^{\circ} \mathrm{C}$ of $14.6 \mathrm{~m} / \Omega \mathrm{mm}^{2}$, modulus of elasticity $19700 \mathrm{kgf} / \mathrm{mm}^{2}$ [4].

Zinc deposits are used to improve the resistance to atmospheric corrosion, in the presence of moisture, natural waters, flue gases, contact with petroleum products or alkaline solutions of medium or low concentration. In tropical climates and in seawater it corrodes strongly [2, 3].

The use of zinc deposits is also due to properties such as the melting temperature of $419.5^{\circ} \mathrm{C}$, density $7.1 \mathrm{~g} / \mathrm{cm}^{3}$, specific heat of $0.0915 \mathrm{cal} / \mathrm{g}{ }^{\circ} \mathrm{C}$, coefficient of linear expansion of $29.81 /{ }^{\circ} \mathrm{C}$, thermal conductivity of $0.27 \mathrm{cal} / \mathrm{cm}^{\circ} \mathrm{C}$, electrical conductivity at $20{ }^{\circ} \mathrm{C}$ of $16.9 \mathrm{~m} / \Omega \mathrm{mm}^{2}$, modulus of elasticity $9400 \mathrm{kgf} / \mathrm{mm}^{2}$ [4].

The paper aims to obtain thin films of nickel and zinc by the magnetron-assisted PVD process using glass plates as support and their characterization from a microstructural point of view, of electrical, optical properties and corrosion resistance.

\section{Experimental conditions}

To obtain the films, nickel and zinc plates of $99.9 \%$ purity, circular with a diameter of $46.5 \mathrm{~mm}$ and a thickness of $1 \mathrm{~mm}$ were used as targets.

A PVD spray deposition system was used [8], in a pressure range between $1 \cdot 10^{-3}-8 \cdot 10^{-3}$ mbar. 
The deposits were made on glass plates, measuring $76 \times 25 \times 1 \mathrm{~mm}$, which were subjected to ultrasonic degreasing with $50 \%$ ethyl alcohol at a temperature of $18-25{ }^{\circ} \mathrm{C}$, for $0.5-1$ minute and then they were rinsed with distilled water for 1-2 minutes and dried.

Ultrasonic degreasing merges the combined degreasing effect of organic solvents with the mechanical effect of ultrasound. These, due to the cavitation phenomenon produced, cause high hydrostatic pressures that lead to the dislocation of fat particles from the samples.

A Neophot 2 optical microscope was used to performed microstructural analysis of the obtained films.

The electrical properties (resistivity), the transparency and the layer thickness of the films have been determined [8].
In the case of thin layers, the resistivity is calculated with the relation:

$$
\rho=\frac{\pi \cdot t}{\ln 2}\left(\frac{U}{I}\right)
$$

where: $\mathrm{t}$ - layer thickness, $\mathrm{U}$ - measured voltage, I applied current.

$$
\frac{\rho}{t}=\frac{\pi}{\ln 2}\left(\frac{U}{I}\right) \quad \text { - represents the surface }
$$
strength of the film.

Also, it was determined the corrosion behavior in the salt fog of the obtained films according to SR EN ISO 9227:2017 for a period of 96 hours.

The regimes used to obtain the films are presented in the Table 1.

Table 1. The deposition regimes of Ni, Zn films

\begin{tabular}{|c|c|c|c|c|c|c|}
\hline $\begin{array}{c}\text { Sample } \\
\text { code / } \\
\text { Material }\end{array}$ & $\begin{array}{c}\text { Tension } \\
{[\mathbf{V}]}\end{array}$ & $\begin{array}{c}\text { Current } \\
{[\mathbf{m A}]}\end{array}$ & $\begin{array}{c}\text { Pressure } \\
{[\mathbf{m b a r}]}\end{array}$ & $\begin{array}{c}\text { Substrate } \\
\text { temperature } \\
{\left[{ }^{\circ} \mathbf{C}\right]}\end{array}$ & $\begin{array}{c}\text { Target - } \\
\text { substrate } \\
\text { distance } \\
{[\mathbf{m m}]}\end{array}$ & $\begin{array}{c}\text { Deposition } \\
\text { time } \\
{[\mathbf{m i n}]}\end{array}$ \\
\hline $\mathrm{P} 1 / \mathrm{Ni}$ & 220 & 110 & $1 \times 10^{-3}$ & 45 & 60 & 20 \\
\hline $\mathrm{P} 2 / \mathrm{Ni}$ & 270 & 120 & $5 \times 10^{-3}$ & 55 & 60 & 20 \\
\hline $\mathrm{P} 3 / \mathrm{Ni}$ & 240 & 170 & $5 \times 10^{-3}$ & 70 & 60 & 20 \\
\hline $\mathrm{P} 4 / \mathrm{Zn}$ & 320 & 100 & $6 \times 10^{-3}$ & 53 & 60 & 20 \\
\hline$P 5 / \mathrm{Zn}$ & 350 & 120 & $7 \times 10^{-3}$ & 60 & 60 & 20 \\
\hline$P 6 / \mathrm{Zn}$ & 360 & 150 & $8 \times 10^{-3}$ & 70 & 60 & 20 \\
\hline
\end{tabular}

\section{Results and discussions}

Following the microscopic analysis, it was observed that the obtained films are glossy, do not show cracks, are relatively homogeneous and adherent, as it can be seen in Fig. 1.

If the current is low, the spray power is low, which reduces the deposition rate. This is due to the lower energy of the argon atoms hitting the target. Thus, a nucleation and a reduced growth take place, which leads to obtaining thinner, non-uniform, discontinuous and inhomogeneous films as it can be seen in samples P1 and P4.

If the current intensity increases, the spray power increases, which leads to an increase in the deposition rate and the film thickness. The mobility of the pulverized atoms and the energy of the adsorbed atoms on the surface are improved, thus increasing the crystallinity of the film, as it can be seen in samples P3 and P6.

It has been found [5-7] that at higher deposition powers there is a Volmer-Weber's growth, respectively an island $3 \mathrm{D}$ growth (through the coalescence of nuclei with the formation of material islands). Thus, uniform, continuous, homogeneous films are obtained with the orientation of the grains perpendicular to the surface, which leads to the improvement of their properties.

Due to the increase of the discharge power, the temperature of the substrate increases which leads to the increase of the degree of crystallinity and of the grain size.

The results of the measurements of electrical resistance, transparency and layer thickness are presented in Tables 2 and 3. 

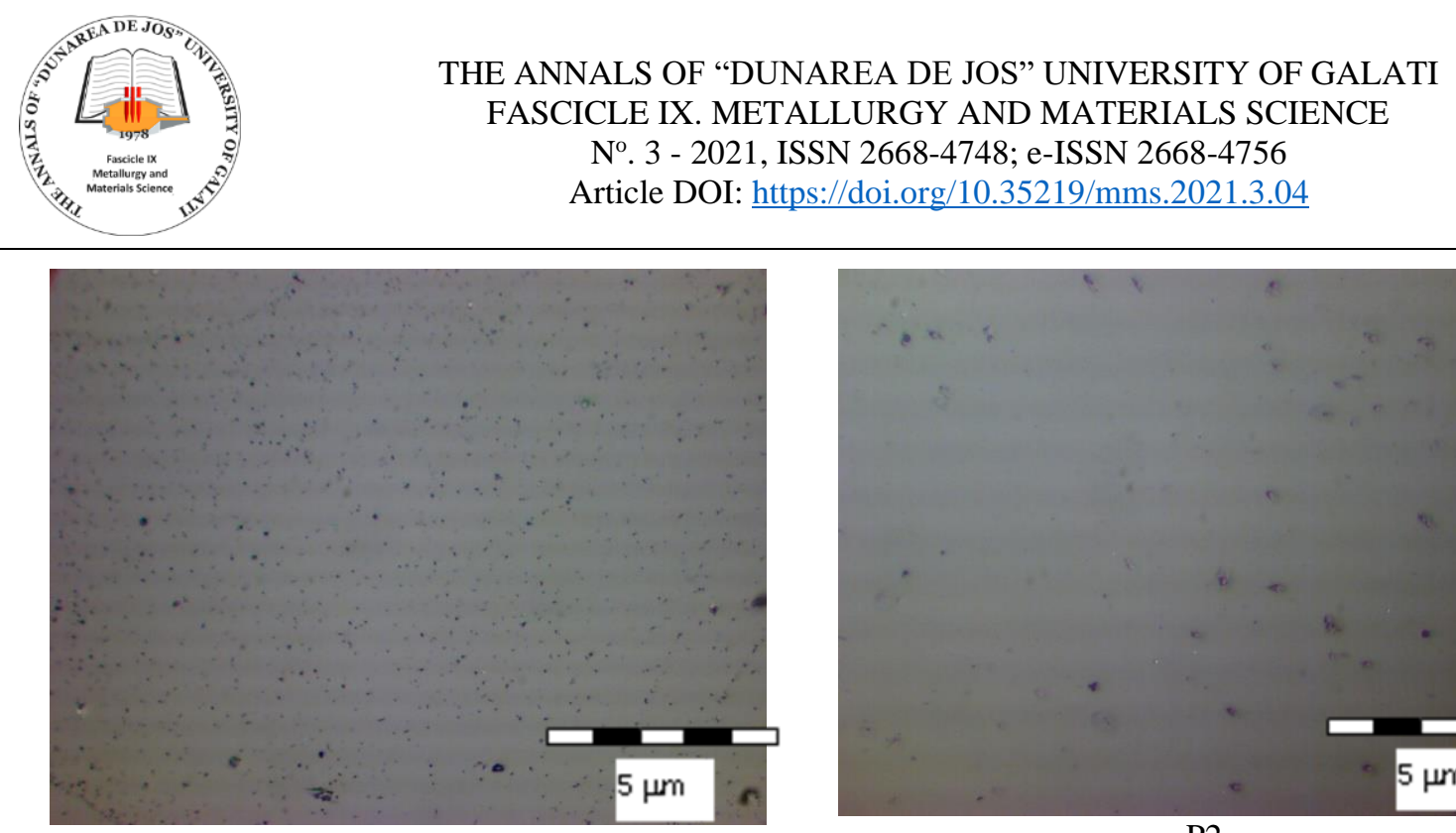

P1
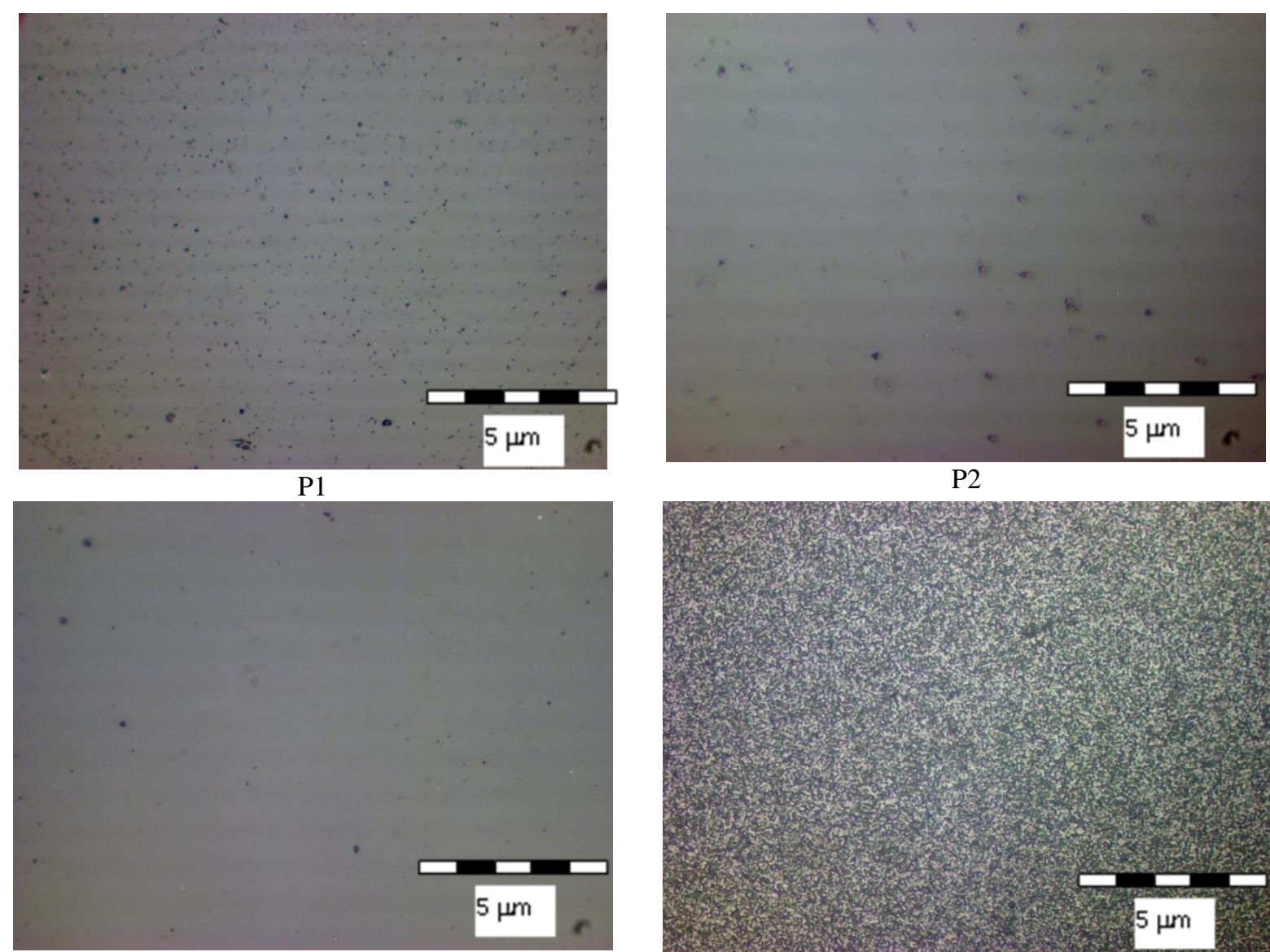

P3

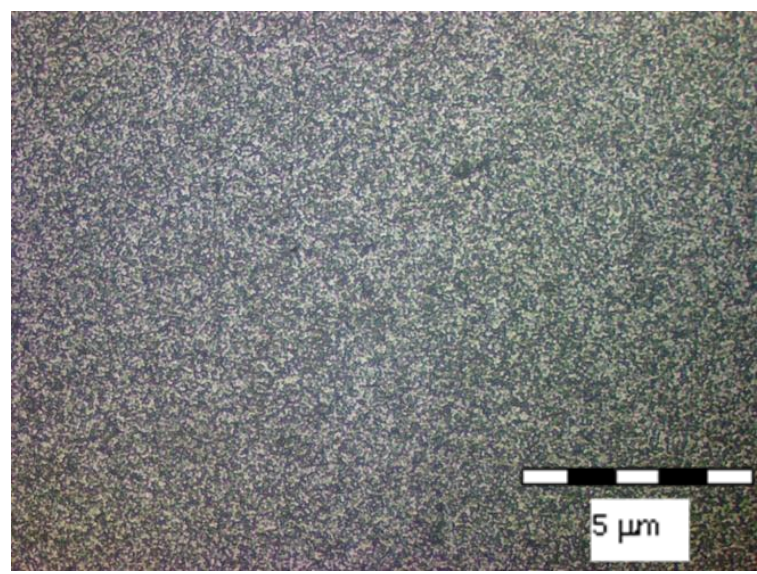

P4
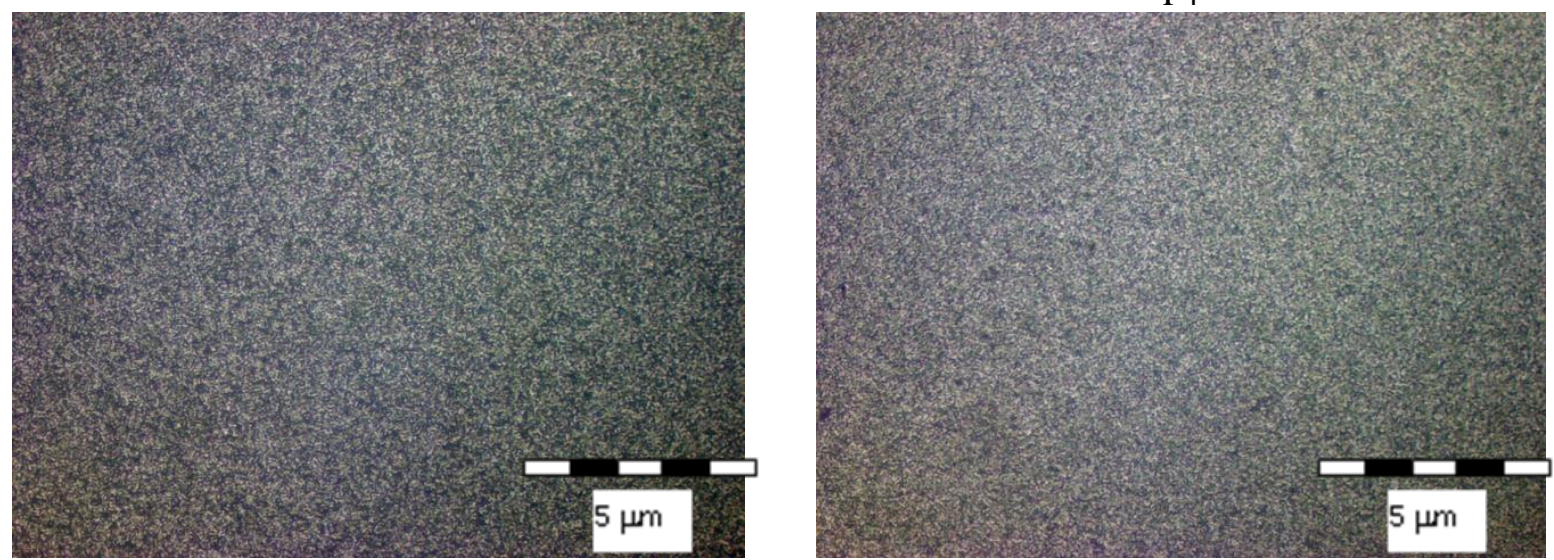

P6

Fig. 1. Micrographs of the deposited films

Table 2. Properties of nickel films

\begin{tabular}{|c|c|c|c|}
\hline $\begin{array}{c}\text { Sample } \\
\text { code }\end{array}$ & $\begin{array}{c}\text { Film surface } \\
\text { resistance Rs } \\
{[\boldsymbol{\Omega}]}\end{array}$ & $\begin{array}{c}\text { Films } \\
\text { transparency }\end{array}$ & $\begin{array}{c}\text { Thickness } \\
\text { of films } \\
{[\mathbf{n m}]}\end{array}$ \\
\hline P1 & 85.16 & 2 & 3.8 \\
\hline P2 & 64 & 0.85 & 5.5 \\
\hline P3 & 17.33 & 0.38 & 33 \\
\hline
\end{tabular}


Table 3. Properties of zinc films

\begin{tabular}{|c|c|c|c|}
\hline $\begin{array}{c}\text { Sample } \\
\text { code }\end{array}$ & $\begin{array}{c}\text { Film surface } \\
\text { resistance Rs } \\
{[\mathbf{M} \boldsymbol{\Omega}]}\end{array}$ & $\begin{array}{c}\text { Films } \\
\text { transparency }\end{array}$ & $\begin{array}{c}\text { Thickness } \\
\text { of films } \\
{[\mathbf{n m}]}\end{array}$ \\
\hline P4 & 12 & 2.25 & 4.6 \\
\hline P5 & 4.5 & 1.8 & 31.5 \\
\hline P6 & 2.8 & 1.2 & 38 \\
\hline
\end{tabular}

Analysing Tables 2 and 3 it can be seen that at low current intensities the discharge power is low, the film thickness is reduced, and the surface resistance is higher. This is attributed to structural defects (dislocations, interstitial defects, vacancies), impurities (foreign atoms soluble in nickel, zinc), low density and crystallinity, due to the reduced mobility of adsorbed atoms. The presence of internal stresses (caused by the difference between the coefficients of thermal expansion between the film and the substrate) in the deposited film increases its susceptibility to oxidation. If the temperature developed during deposition is low, the value of these voltages is negligible.

As the current intensity increases, the discharge power increases, the film thickness increases and the surface resistance decreases. The decrease is due to the improved film density and increased grain size. The density of dislocations, the probability of defects occurring and the micro-tensions in the film decrease as its thickness increases.

The transparency of the films decreases as the current intensity increases, respectively as the spray power increases. This is due to the increase in film thickness.

The corrosion behavior in the salt mist was performed on the samples with the highest thickness. Analysing Figure 2, it can be seen that the nickel film has a higher corrosion resistance than the zinc film. Corrosion has been found in points that evolve over time, as surface passivation occurs.

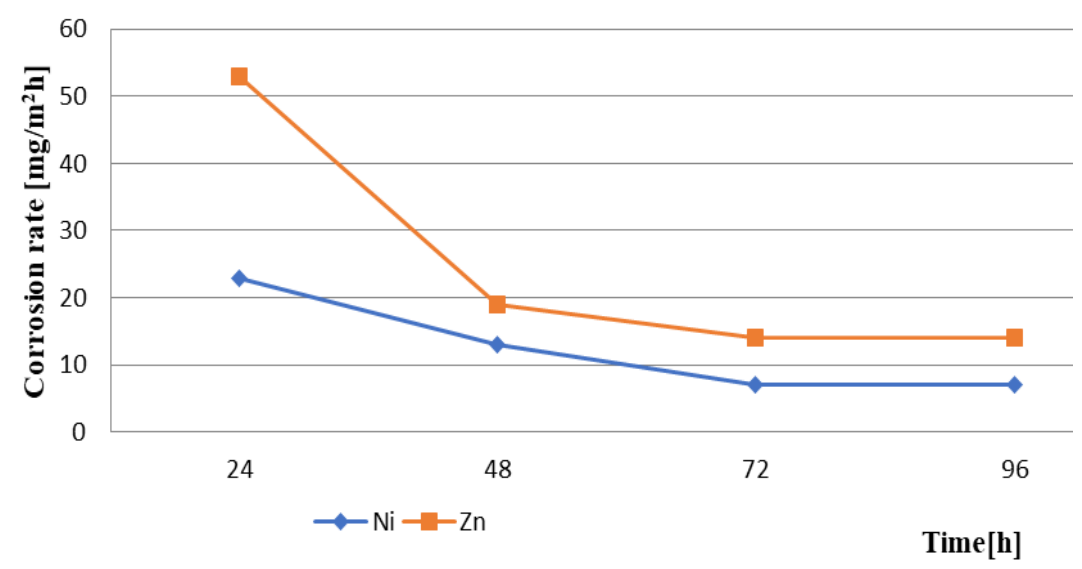

Fig. 2. Corrosion behavior of deposited films

\section{Conclusions}

The following conclusions can be drawn from the experiments performed:

- magnetron-assisted spraying is used in many fields, to obtain thin films and ensures a rigorous, advanced control over the composition and microstructure and implicitly over their properties;

- the obtained films are glossy, they do not show cracks, and they are even more homogeneous and adherent, the higher the current intensity, the higher the spray power; thus, increasing the film thickness from 3.8 to $33 \mathrm{~nm}$ for nickel deposits and from 4.6 to
$38 \mathrm{~nm}$ for zinc deposits and grain size and improving the crystallinity;

- as the current intensity increases, the surface resistance decreases because the density of the film improves and the probability of structural defects, impurities and increase of micro-tensions is reduced; thus, it has values between 85.16 and $17.33 \Omega$ for nickel deposits and between 12 and $2.8 \Omega$ for zinc deposits;

- the transparency of the films is reduced with the increase of the spraying power and their thickness; it has values between 2 and 0.38 for nickel deposits and between 2.25 and 1.2 for zinc deposits; 


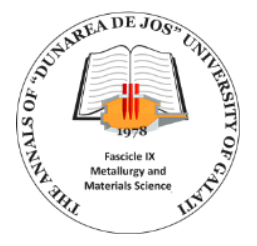

- the corrosion behavior in salt mist of nickel film is superior to zinc film.

\section{References}

[1]. Vermeșan G., et al., Introduction to surface engineering, Dacia publishing house, Cluj-Napoca, 1999 (Introducere în ingineria suprafețelor, editura Dacia, Cluj-Napoca, 1999).

[2]. Maria Constantinescu, Corrosion protection of metals, Technical Publishing House, Bucharest, 1979. (Protecţia anticorozivă a metalelor, Editura Tehnică, București, 1979).

[3]. Marinescu A, Andonianţ Gh., E Bay - Electrochemical and chemical technologies for the protection of metallic materials, Bucharest Technical Publishing House, 1984 (Tehnologii electrochimice şi chimice de protectie a materialelor metalice, Editura Tehnica Bucureşti, 1984).
[4]. Schumann H., Physical Metallurgy, Technical Publishing House, 1962 (Metalurgie fizică, Editura tehnică, 1962).

[5]. Mech K., Kowalik R., Zabiński P., Cu thin films deposited by dc magnetron sputtering for contact surfaces on electronic components, Archives of Metallurgy and Materials, Issue 4, vol. 56, 2011.

[6]. Minh-Tung Le, Yong-Un Sohn, Jae-Won Lim, Good-Sun Choi, Effect of Sputtering Power on the Nucleation and Growth of $\mathrm{Cu}$ Films Deposited by Magnetron Sputtering, Materials Transactions, vol. 51, No. 1, p. 116-120, 2010.

[7]. Ali Gelali, Azin Ahmadpourian, Shahoo Valedbagi, Behroz Safibonab, Bandar Astinchap, Eisa Karimzadeh, Structure and Morphology of the Cu Films Grown by DC Magnetron Sputtering, J. Basic. Appl. Sci. Res., 3(6), p. 846-849, 2013.

[8]. Boiciuc S., CuO films obtained by oxidation of cu layers deposited by the pvd process - magnetron sputtering, The Annals of "Dunarea de Jos" University of Galati, Fascicle IX. Metallurgy and Materials Science, no. 3, 2020. 